\title{
'Does everybody understand?' Teacher questions across disciplines in English-mediated university lectures: An exploratory study
}

\author{
Emma Dafouz Milne \\ edafouzm@ucm.es \\ Universidad Complutense de Madrid, Spain \\ Davinia Sánchez García \\ mariadavinia.sanchez@udima.es \\ Universidad a Distancia de Madrid, Spain
}

\begin{abstract}
This small-scale study attempts to analyse the role of English as a medium of instruction (EMI) in three different university lectures across disciplines. Following previous research (Crawford Camiciottoli 2004, Dafouz 2011, Dalton-Puffer 2007), the focus is placed on teacher discourse and, more specifically, teacher questions as fundamental tools that articulate classroom talk and prime strategies that promote interaction and co-construct meanings (Chang 2012, Sánchez García 2010). Our corpus includes four hours of teaching practice from Spanish EMI lessons where participants are non-native speakers of the vehicular language. Preliminary results suggest that questions tend to be greatly exploited discursive features and that confirmation checks and display questions seem to predominate over all other types of questions used in the classroom. Concurrently, the study suggests that there seem to be more commonalities than differences in the use of questions across disciplines. Additionally, it can be stated that lecturers need to be trained to benefit from the resources offered by their own discourse in order to facilitate students' content and language learning.
\end{abstract}

Keywords: English as a medium of instruction, CLIL, teacher questions, language awareness, classroom discourse.

\section{INTRODUCTION}

In the last decade, learning through English as a medium of instruction (or EMI) has become a widespread trend all over Europe. The driving forces leading to the expansion of this teaching and learning practice were grouped by Coleman (2006: 4) in seven categories, namely, internationalization of higher education, student exchanges, teaching and research materials, staff mobility, graduate employability, the market in international students, and Content and Language Integrated Learning (hereinafter CLIL). CLIL approaches, in the specific case of Spain, have been largely implemented at primary and secondary school levels as a top-down strategy stemming from the 
respective regional governments. In the case of tertiary education, however, CLIL implementation strategies (or rather EMI strategies) ${ }^{1}$ are mostly decentralized and follow a rather heterogeneous fashion with universities embarking on ambitious internationalization plans that, amongst other measures, promote English as the language of instruction both in undergraduate and postgraduate degrees (Dafouz and Núñez 2009, Dafouz et al. in press, Doiz et al. 2013, Fortanet-Gómez 2013).

Due to the rapidly growing pace of EMI instruction across settings, studies that attempt to throw light on this situation have multiplied and, concurrently, reflect the diversity of interests and concerns amongst scholars and practising teachers. In this line, EMI research spans, for example, from studies on classroom discourse and school practices, teacher cognition and beliefs, to the role of English as an international language or lingua franca in multilingual institutions (see Smit and Dafouz 2012: 1-12 for a detailed account of these matters). Within these macro research concerns, one of the specific aspects to which attention needs to be drawn is that of teacher discourse. The reason is two-fold: on the one hand, because in teacher talk students have to face complex discourses both from a conceptual (disciplinary) and a linguistic (foreign language) perspective; on the other hand, because it is essential to raise awareness, especially amongst the content specialists, of how teacher discourse can be used pedagogically to support students in their learning process. Given the wide set of features that may be analysed in teacher classroom discourse, our work will focus on the specific use that teachers make of questions in EMI settings. We are specifically interested in the role that questions play in the construction of learner knowledge, as they are one of the main devices that teachers use to co-construct meaning with learners. In this line, some of the initial research conducted thirty years ago already showed that teachers ask, on average, two questions a minute (Edwards and Mercer 1987). Admittedly, although the study of questions is not novel in the educational context and its centrality in the teaching and learning process has been discussed extensively (see Cazden 1988, Csomay 2002, Dillon 1988, Mehan 1979, Thompson 1998, van Lier 1996, Wu and Chang 2007), research into the roles and types of teacher questions used in EMI university contexts by

\footnotetext{
${ }^{1}$ The acronym EMI (English as the Medium of Instruction) rather than CLIL will be used throughout this study as it reflects more appropriately the content-oriented focus adopted by the universities taking part in our research. For terminological considerations regarding EMI/ICL/CLIL distinctions see Smit and Dafouz (2012: 4-5).
} 
non-native content teachers is much less frequent. In addition, we intend to examine the use of questions from a cross-disciplinary perspective in order to discern possible relations between the academic disciplines under scrutiny (i.e. business studies, engineering and physics) and the presence (or absence) of certain question-types. Here we follow Dillon (1988: 115) when he rightly observed that although most "classrooms are full of questions [however, they are often] empty of inquiry since those who ask questions in school - teachers, texts, tests - are not seeking knowledge; [and] those who would seek knowledge - students - are not asking questions at all”. Given this paradox, our study aims to answer the following:

- RQ 1: Are questions used in EMI classrooms? If so, what kinds of questions do teachers actually utilize in their lectures?

- RQ 2: What discourse function(s) are implemented through the questions used by teachers in lectures?

- RQ 3: Do the types of questions displayed vary depending on the disciplines taught?

- RQ 4: Do teacher questions actually trigger student participation?

\section{THEORETICAL FRAMEWORK}

\section{II.1. Learning as a social and interactive process}

Vygotskyan and neo-Vygotskyan approaches to learning and teaching underline the importance of learning as a social process and the role of discourse to enable the social construction of knowledge (Gibbons 2002, Mercer 2000, van Lier 1996, Vygotsky 1978, 1989). In Gibbons's words “the kinds of talk that occur in the classroom are critical in the development of how students learn to learn through language and ultimately how they learn to think" (2002: 25). From a social-interactionist perspective, it is important for students to engage in social classroom events that trigger off the thinking process and develop students’ conceptual knowledge.

Interaction has been identified as playing a key role, since learning is viewed not only as an individual cognitive learning process but also as a social one, and learning occurs during the interactions that take place between individuals. In view of these principles, it is important that teachers promote student participation and foster negotiations of 
meaning in the classroom so that learners are provided with opportunities to develop their cognitive ability, improve their linguistic skills and boost their learning process.

Moreover, from a second language acquisition angle, the additional claim is that interaction also provides opportunities for foreign language learning and development (Swain 1985, 1995, Long 1981, 1983). The research carried out in this line reveals that considerable amounts of high-quality comprehensible input (Krashen 1985) and opportunities to produce output through the interaction that takes place when negotiating meanings (Lyster 2007) may push students’ L2 language learning.

\section{II.2. Teacher questions in university lectures}

The importance of interaction in university lectures is also gaining weight, in spite of the traditional assumption that tertiary education is mostly teacher-fronted and monologic (Goffman 1981). In fact, a number of recent studies claim that university lectures are gradually shifting away from being "an institutionalized extended holding of the floor" (Morell 2007: 223, Crawford Camiciottoli 2004) and becoming the means of a much more egalitarian and participatory methodology in which the role of the instructor is also moving from the main figure of knowledge-provider to that of facilitator in the learning process. As a result, much research has been conducted on the various textual and interpersonal discursive features that seem to promote more interactive lectures (Dafouz Milne and Núñez Perucha 2010, Morell 2004), by using different discourse structuring devices (Crawford Camiciottoli 2004, Young 1994) or by focusing on the use of questions across disciplines (Chang 2012, Sánchez García 2010, Thompson 1998).

By and large, whatever the educational context or level, questions seem to be key tools in the communicative exchanges that ensure a natural and equal interaction in the classroom (Sánchez García 2010). In the case of university lectures, they also seem to be one of the strategies that lecturers employ for very diverse reasons: to ease comprehension, support students' learning process, establish collaborative meaningmaking amongst participants, test learners' knowledge, elicit information and avoid communicative breakdowns, among other things. Given the multi-faceted nature of 
questions, the next section will tackle the myriad of typologies that have been used in the literature.

\section{II.3. Classroom question typologies}

Much ink has been spilt on the nature of questions (Cazden 1988, Chaudron 1988, Tharp and Gallimore 1988) and different classifications of these textual devices have been offered. Thompson (1998), for example, divided questions into audience-oriented and content-oriented devices, thus focusing on whether they addressed the learners and required their oral participation, or rather concentrated on the topics and subjects being dealt with. In her analysis of CLIL secondary classes in Austria, Dalton-Puffer (2007) maintained two well-established binary oppositions: (i) display and referential questions (following Mehan 1979) and (ii) open versus closed questions (Barnes 1969). The first polarity refers to whether the answer to the question is actually known by the questioner (i.e. display) or unknown (i.e. referential), while the second polarity distinguishes between those questions whose answers are limited to a 'yes' or 'no' response (i.e. closed) and those which allow for a more linguistically elaborated reply (i.e. open).

Answers to display questions are typically reduced and include a very limited number of words while referential questions have usually been defined as triggers of more authentic, longer, more complex and more involved responses on the part of the students. As a result, they may foster students' output and give them better opportunities for language production. Hence, it is believed that a high number of referential questions are ideally expected in classrooms, although some studies (Dalton-Puffer 2007, Long and Sato 1983, Musumeci 1996, inter alia) reveal that teachers tend to use more display questions than referential ones.

Dalton-Puffer (2007: 123-255) elaborates a further classification regarding the goal of questions in classroom settings and thus makes a distinction between questions for facts, questions for explanations, questions for reasons, questions for opinions and metacognitive questions, all of which can be 'moves' performed by either the teacher or the students.

In this study a combination of two taxonomies was adopted to categorize questions: Dalton-Puffer's (2007) model in CLIL secondary classrooms, and Sánchez García’s 
(2010) proposal on EMI university lectures. The resulting taxonomy, displayed below, integrates Dalton-Puffer's categories with some new ones to adapt better to the data found, while it also makes a distinction between questions (or moves) initiated by the teacher, questions initiated by students and questions asked by both sets of participants. Table 1 displays the taxonomy employed in the present analysis ${ }^{2}$ :

Table 1. Question Taxonomy used in the study.

\begin{tabular}{|l|l|l|}
\hline \multirow{2}{*}{ MOVES BY TEACHERS } & MOVES BY STUDENTS & $\begin{array}{l}\text { MOVES BY TEACHERS AND } \\
\text { STUDENTS }\end{array}$ \\
\hline Display questions & Questions seeking explanations & Confirmation checks \\
\hline Referential questions & Questions seeking confirmation & Procedural questions \\
\hline Rhetorical questions & & Indirect questions \\
Retrospective questions & & Repetition questions \\
Self-answered questions & & Language questions \\
\cline { 3 - 3 } & &
\end{tabular}

As indicated in Table 1, the question types analysed in the present study are (i) display questions, whose answer is known by the teacher, and uses them to find out the actual knowledge of students on a certain topic (e.g. “what are the advantages of exporting?”), (ii) referential questions, whose answer is not known by the teacher (e.g. "what sorts of ideas have you come up with?”), (iii) rhetorical questions, which are questions to which no answer is expected and are meant to make the audience think and reflect on something (e.g. "how can we face those industries?”), (iv) self-answered questions, which are immediately answered by the speaker himself/herself (e.g. "is it possible to be leading in one country and being completely inexistent in another?" "Yeah, it's possible. It happens”), (v) retrospective questions, which make hearers go back in time to revise some issues (e.g. “remember back to the uh, second class?”), (vi) confirmation checks, which aim at ensuring the audience's understanding of the topic/lecture (e.g. “OK? Do you understand?”, “pardon?”, “excuse me, what do you mean by that?”, “did you say...?”), and (vii) repetition questions, which repeat the last word, utterance, idea or argument expressed (e.g. “increase demand, what was the second thing?”).

\footnotetext{
${ }^{2 \square}$ For reasons of scope and space, this study will only focus on those questions articulated by lecturers in their discourse.
} 


\section{METHODOLOGY}

\section{III.1. Data collection}

The data gathered in order to answer the research questions consist of three university lectures conducted in English. The teachers and most of the students attending the lectures (with the exception of a low number of foreign students on Erasmus exchange programmes) are native speakers of Spanish and, therefore, English is treated in this context as a foreign language. The data used is a subset of the lectures gathered by the research group CLUE (Content and Language in University Education) based at the Universidad Complutense de Madrid ${ }^{3}$. The three lectures analysed, which were first videotaped and then transcribed manually, were gathered from three different universities in Madrid: Universidad Rey Juan Carlos, Universidad Carlos III, and Universidad Politécnica de Madrid. These universities were chosen by means of criterion sampling (Duff 2008) drawing on two major decisions: a) different lecturer profiles (i.e. prior experience in EMI instruction) and b) different disciplines under scrutiny (i.e. business, engineering and physics). As shown in Table 2 below, our data account for 240 minutes of teaching practice and a total of 30,209 words pertaining to the three different disciplines mentioned above.

Table 2. Data description.

\begin{tabular}{|l|l|l|l|l|}
\hline LECTURE & DURATION & $\begin{array}{l}\text { WORD } \\
\text { COUNT }\end{array}$ & TOPIC & UNIVERSITY \\
\hline Business & 90 minutes & 11,321 & $\begin{array}{l}\text { Company } \\
\text { internationalization }\end{array}$ & $\begin{array}{l}\text { Universidad Rey Juan } \\
\text { Carlos }\end{array}$ \\
\hline Physics & 93 minutes & 13,450 & $\begin{array}{l}\text { Mono- and poly-crystals } \\
\text { strong obstacles }\end{array}$ & Universidad Carlos III \\
\hline Engineering & 57 minutes & 5438 & Displacement of engines & $\begin{array}{l}\text { Universidad Politécnica de } \\
\text { Madrid }\end{array}$ \\
\hline Total & 240 minutes & 30,209 & \multicolumn{2}{|l}{}
\end{tabular}

\footnotetext{
3 The CLUE Project (Content and Language in University Education, REF: GR60/09) is a consolidated research group founded in 2006 and coordinated by Dr. Emma Dafouz. The project has worked under the CLIL/EMI umbrella terms distributing questionnaires, gathering and analysing data to provide a quantitative and qualitative evaluation of the implementation of CLIL/EMI and internationalization strategies in Spanish tertiary contexts.
} 
The three lectures chosen for the study belong to three different disciplines in order to not only provide an account of how English as a foreign language is used as a medium of instruction in tertiary education, but also to consider any possible differences and similarities across disciplines.

Content-wise, the Business session develops around the concept of company globalization and internationalization. It is part of a course in the bachelor's degree of Business Administration. The Physics lecture focuses on the behaviour of mono- and poly-crystals in deformation and on strength mechanisms for weak and strong obstacles. It took place within a BA programme on nuclear physics. Finally, the Engineering lecture has displacement of engines as the main topic and was part of a BA degree in engineering. The three lecturers are specialists in the content matter and for all three English is a foreign language.

\section{2. Data analysis}

The aforementioned data were analysed using the following procedure. All three lectures were transcribed manually from videotapes provided by the CLUE research group. This was followed by the identification of all the instances of questions occurring in the transcripts. Second, a qualitative approach was accomplished, which resulted in the functional classification of the different types of questions ${ }^{4}$. For analytical purposes, a question was identified not only on the basis of its syntactic form (i.e. inversion, wh- words, etc.) but also on the intonation and utterance function. In the functional analysis, a number of questions proved to be clearly multifunctional, meaning that there was no one-to-one relationship between its linguistic form and discourse function. Thus, a context-sensitive analysis of each question had to be conducted prior to its final classification. Chang (2012: 110) also reported on this issue of multi-functionality, suggesting that the more common the question form was, the more variable its functions were.

Third, the categorization was complemented with a quantitative analysis by calculating the frequency of use of the aforesaid linguistic phenomena in order to get a clearer

\footnotetext{
${ }^{4}$ In order to guarantee inter-rater reliability, the two researchers initially coded questions independently, following the chosen taxonomy, and later checked for agreement. Cases for which there were different codes were re-examined and consensus was reached.
} 
account of the findings encountered and ease the comparison of the three lessons. For comparative purposes, and given that the lectures differ in length, results have been normalized taking into account the number of questions occurring per 1000 words ${ }^{5}$. The results were displayed both using percentages (when the lectures were not compared across disciplines but treated collectively) and normalized findings (when compared cross-disciplinarily). A number of excerpts from the dialogues in the lectures are included to illustrate the discussion of results.

\section{RESULTS AND DISCUSSION}

In the four hours of teaching practice analysed, a total of 13.9 questions per 1000 words were identified, a finding that offers a positive answer to the first part of our research question 1 (RQ1), that is, that questions are indeed used in EMI classrooms as in other teaching contexts. The second part of RQ1 referred to the types of questions that lecturers utilized in their sessions and the study reveals that the four more frequent question types in our data are confirmation checks (50\%), followed by self-answered questions (22\%), display questions (20\%) and, finally, referential questions (8\%) as Figure 1 below shows:

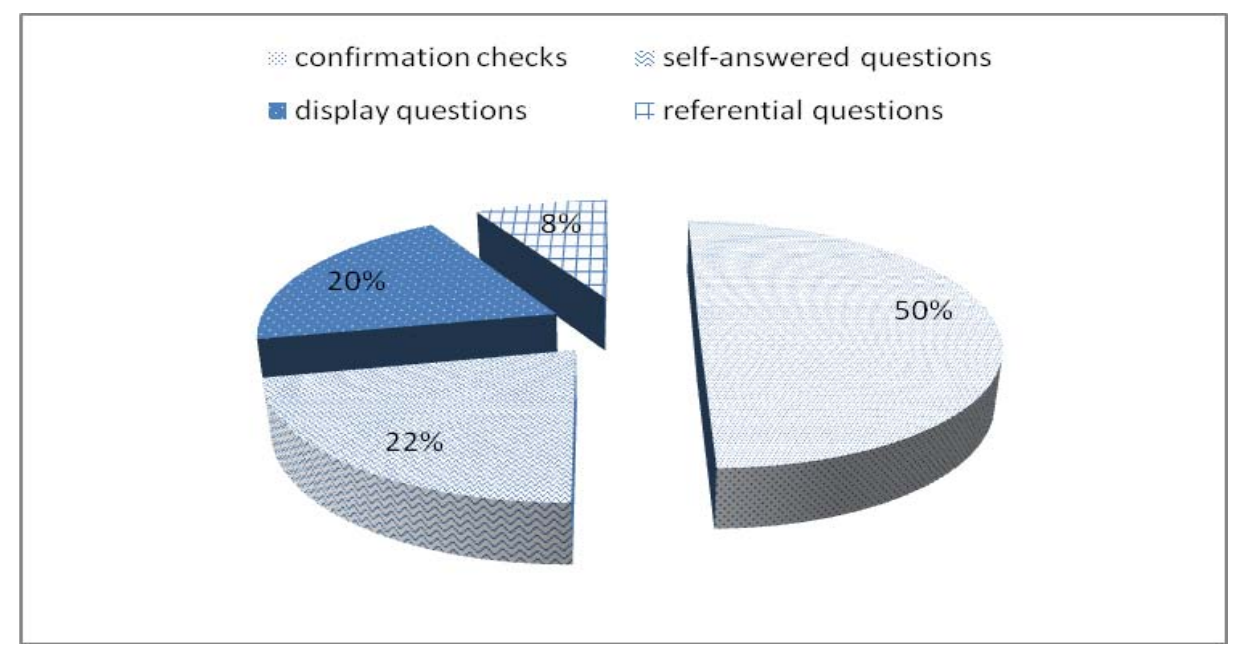

Figure 1. Most frequent question types in EMI classrooms.

\footnotetext{
${ }^{5}$ Normalization is a common way to convert raw counts into rates of occurrence, so that the scores from texts of different lengths can be compared (see Biber 1993 for a full account of this frequently used method).
} 
By types, confirmation checks are the most commonly used type of question in the three lectures examined, regardless of the discipline. From a quantitative perspective, our findings differ notably from Chang's study (2012: 109) in terms of the frequency of comprehension checks on academic divisions similar to ours (namely, Humanities and Arts, Social Sciences and Education, and Physical Sciences and Engineering). In Chang's work the frequency of questions used by native English-speaking lecturers to check student's comprehension was especially low. Although Chang does not provide further explanations to this finding, when compared to our study, one could argue that in Chang's paper (with data drawn from the MICASE corpus) both lecturers and students have English as their native or first language and thus comprehension problems derived from language difficulties will most likely not be so relevant. In contrast, the lecturers and students in our research have English as a foreign language, a difference which may have an effect on both the way lecturers articulate their discourse (Thøgersen and Airey 2011) and/or in the way students understand it.

On a more refined level, and in order to seek possible reasons regarding the striking numerical differences between Chang's study and our own, we revised the composition of these units qualitatively and discovered that $89.9 \%$ of the questions classified as comprehension checks corresponded to the form 'OK?'. The example below illustrates a typical instance found in our data:

(Example 1) I mean, for instance, imagine, there is an activity, the research and development. It is carried out in one particular country. It can lead you, it could lead you to have losses, OK? (pause) No problem with that in that particular country, but in the global... When considering it global, you will make more profit. Do you know what I mean? But the point is that you are trying to maximize the value on a global basis, considering everything, OK? (pause) So, that's it.

In a more detailed analysis, we realized that the majority of these confirmation checks were not actually (or not only) directed by the teachers in our data to the studentaudience so as to verify whether they follow the ideas in the lectures adequately. In our data this device seems to be largely used as a transition marker, in that, when uttered, the lecturer is making a short pause to think about the next coming idea. In other words, it looks as if the primary goal of those "first-approach" confirmation checks used by lecturers is not to obtain verification from students but rather from himself/herself and could often be translated in teachers' minds as “OK, this point is covered, let's move on 
to the next one”. As far as our three teacher subjects are concerned, our data suggest that when in search of audience agreement, lecturers use other types of confirmation checks, that may be either more explicit (e.g. do you understand?, is it clear?) or more extended (e.g. is it OK?), while at the same time they pause for a few seconds seeking, maybe, some verbal or non-verbal response from students. In any case, in our sample these checks are rather scarce.

Regarding research question 3 (RQ3), by disciplines, confirmation checks appear in the Business class 5.8 times per 1000 words, 3.8 were produced in the Engineering realm, and 2.7 in Physics, as shown in Figure 2.

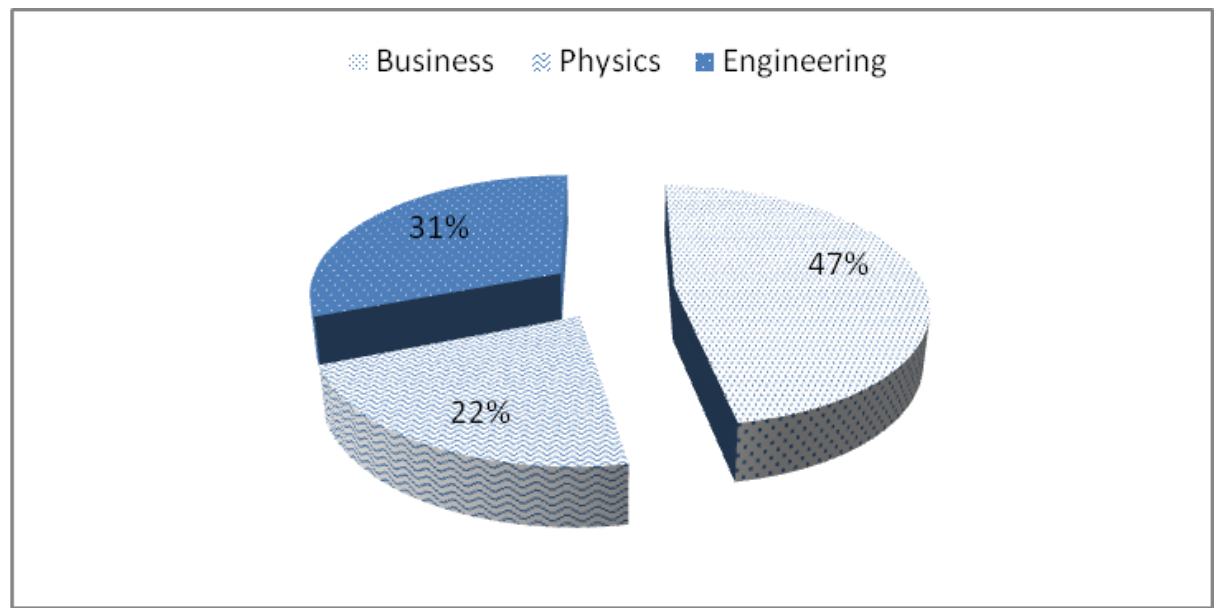

Figure 2. Confirmation checks by disciplines.

From this disciplinary point of view, this time our results do match Chang's study (2012), since it also yields a higher number of comprehension checks in the Social Sciences, or 'soft sciences' (Neumann 2001), than in the Physical Sciences and Engineering, or 'hard sciences'. For Chang (2012: 113), this result could be linked to differences in the disciplinary cultures examined and thus concludes:

\begin{abstract}
In the hard fields, the process of knowledge production is cumulative in nature; more shared background knowledge and standard procedures of knowledge making can thus be established. Due to this characteristic of knowledge production, the professors in these fields have developed a less interactive style of lecture discourse. [In contrast] the process of establishing new knowledge in the soft fields tends to be more persuasive and dialogic in nature and does not show the same linear developmental patterns as that in the hard fields. In conjunction with the less hierarchical power structure among the community members, this fact might explain why professors in the two soft divisions tend to use questions to engage their students and to manage the teaching flow slightly more often than their counterparts in the hard fields.
\end{abstract}

Although the reduced size of our dataset calls for great caution in the reading of the findings, it does trigger off interesting questions regarding disciplinary differences in 
the construction of knowledge and, concurrently, in interactional classroom behaviour (Neumann 2001).

Self-answered questions were the second most frequent question type in all three lectures except in Engineering, where they were outnumbered by display and referential questions. As seen in Figure 3, once again the Business lecture is the one containing the highest number of questions ( $\mathrm{n}=4$ per thousand words), followed by the Physics session ( $\mathrm{n}=1.1$ per thousand words) and finally the Engineering lecture $(\mathrm{n}=0.3$ per thousand words).

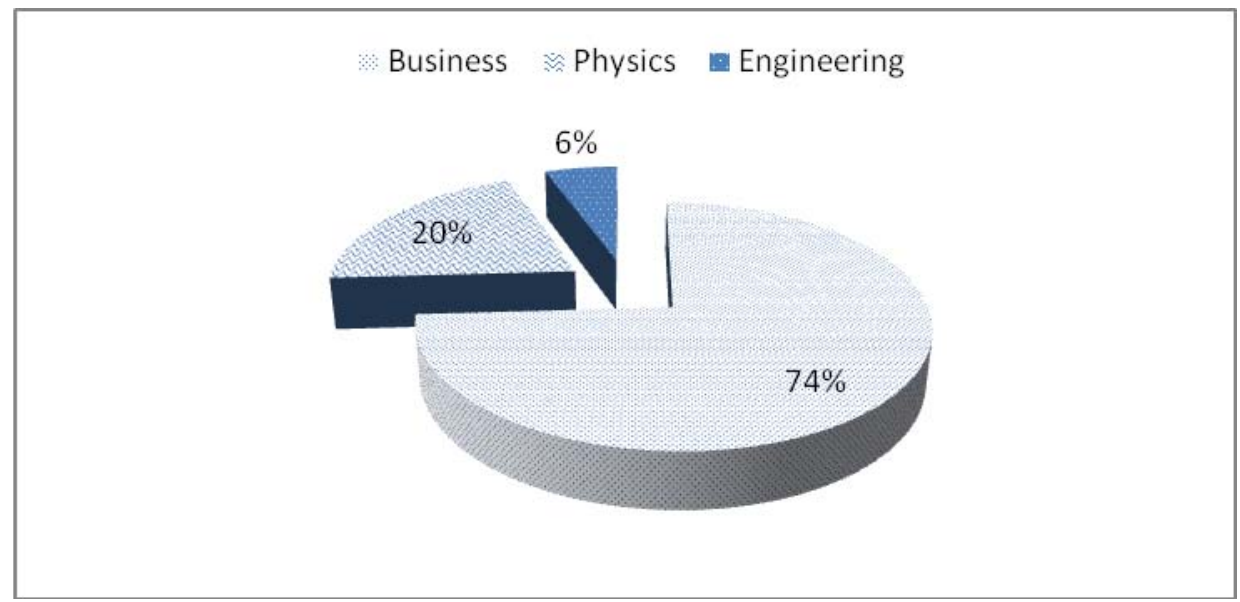

Figure 3. Self-answered questions by disciplines

These types of questions do not seem to favour an intervention on the part of the students since the teacher offers a prompt reply with no pause, as if he/she were talking to himself/herself while paving the way for the next point in the lecture or the further development of an idea. On the basis of this finding, we coincide with Bamford's study (2005) when she views lecturers' control of both the question and answer as an effective attention-focusing mechanism. Bamford suggests that by reproducing the prosody of spontaneous conversation, such question/answer sequences can "serve to induce the student into thinking that what is taking place is an interactive sharing of ideas and information” (Bamford 2005, quoted in Chang 2012: 126).

Additionally, self-answered questions also seem to play a discourse guiding function, meaning that they may be used by the lecturer in guiding himself/herself through the unfolding speech so that new topics or subtopics can be introduced or developed. Both of these functions can be traced in the examples below: 
(Example 2) Teacher: what happens if another dislocation is coming after this one? It will find not only the obstacle, but also the dislocation loop in here. So, it will have a more complex interaction.

(Example 3) Teacher: (...) I have a carbon precipitate. I have just some impurities of carbon in my matrix, but they are just what is called a solid solution (...) What happens? We can have two possibilities. If the impurity atom it is of smaller size than the one from the matrix, then we will have some tensile stresses on the surrounding lattice. While if we have that the impurity it is bigger one, then I will have compressive stresses in the lattice.

Finally, display and referential questions, although present in all three lectures, show certain differences when it comes to their frequency of use, as Figure 4 shows. Overall, there are 4.9 display questions and 2.1 referential ones.

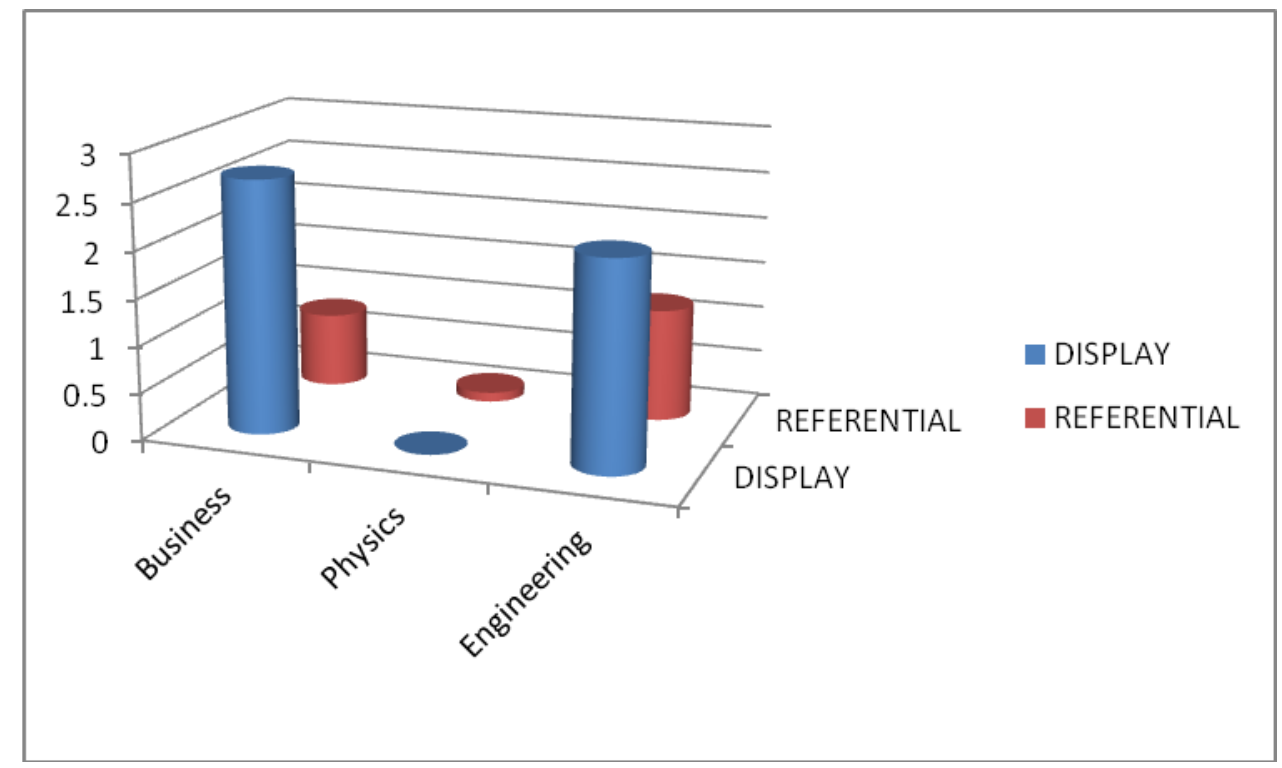

Figure 4. Display and referential questions by disciplines.

As shown in Figure 4 above, display questions (2.7) are clearly more numerous than referential ones (0.8) in the Business lecture. In the same vein, display questions (2.2) nearly double referential ones (1.2) in the Engineering session. As a counterpoint, display (0) and referential questions (0.1) barely take place in the Physics classroom. Again, our findings match Chang's study (2012) in that more audience-oriented questions than content-oriented questions are found in the Social Sciences and fewer in the Physics and Engineering divisions.

From a second language acquisition perspective, referential questions, as was mentioned earlier, are believed to trigger longer, more authentic and more involved contributions on the part of the student than display questions (Dalton-Puffer 2007: 96). 
The reason for this lies in the genuine interrogative nature of referential questions, whereby participants exchange real information unknown to the teacher and most likely to their fellow students. Nevertheless, in our data, students' output to referential questions was extremely limited and often reduced to minimal responses as the examples below illustrate. This finding could be tied in to the fact that most referential questions are formally closed. In other words, they only offer the audience the possibility of answering with "yes" or "no" responses as shown in examples 4, 5 and 6:

(Example 4) Teacher: Some question about the theory that we saw yesterday? Student: No.

(Example 5) Teacher: Have you seen that the commercials for Volkswagen have been reproduced in German all around the world, even here?

Student: Yes.

(Example 6) Teacher: you wouldn't be efficient if you only produced mobile phones for Swedish people, OK? Or Norwegian people, imagine. How many Norwegians can there be?

Student: four million.

Teacher: four million, puff.

Once again, although these questions in theory present an excellent opportunity to create a conversational exchange between participants, in most cases either no output (see example 4) or very reduced discourse (i.e. one- or two-word responses) was produced by students as examples 7 and 8 reveal; that is, short exchanges with few words and simple grammar.

(Example 7) Teacher: what phases are you comparing?

Student: atom

Student: field

(Example 8) Teacher: how much phase does the field go through in the time interval between the pulses?

Student: um... (that) length?

On the whole, these findings inevitably prompt a reflection on the role of questions in lecture discourse and in classroom learning in general. Moreover, it also brings to the foreground issues of teaching methods in university settings. In this line, Musumeci (1996) suggested that interaction in university lectures was not to be expected by either teachers or students as lectures were not the appropriate genre for interactional exchanges to occur in. To look into this matter, prospective work could take into 
account classroom dynamics and the overall teaching aim of university lectures, as indeed in many cases the most important aspect of these sessions may not be classroom interaction after all.

Research question 4 (RQ4) concerning the relationship between teacher questions and student interaction still needs to be answered. By participants, it is interesting to highlight that 9.6 questions out of the overall 13.9 questions per 1000 words were teacher-initiated questions, whereas only 4.3 were questions articulated by students. Analysis of the data already showed that the number of questions uttered by teachers is not a transparent sign of classroom interaction. In other words, teacher questions do not necessarily correlate with student response, as the table below shows:

Table 3. Questions per 1000 words - interaction correlation.

\begin{tabular}{|l|l|l|l|l|}
\cline { 2 - 5 } \multicolumn{1}{c|}{} & BUSINESS & PHYSICS & ENGINEERING & TOTAL \\
\hline Total Questions & 15.3 & 4.6 & 8.1 & 28 \\
\hline $\begin{array}{l}\text { Total questions } \\
\text { triggering student } \\
\text { interaction }\end{array}$ & 5.7 & 2 & 4.4 & 12.1 \\
\hline
\end{tabular}

However, the findings also suggest that the more numerous the teacher questions are, the higher the chances of student response will be. For example, the Business lecture is the one containing the highest number of questions $(n=15.3)$ and consequently the one that yields the highest level of student response or interaction (5.7 instances). The Engineering lecture appears in second place with a total of 8.1 questions, out of which 4.4 trigger interaction. And finally, the lecture producing the fewest conversational exchanges as the result of questioning is the Physics session with 4.6 questions and 2 cases of interaction per thousand words. In any case, and in a rough calculation, less than $50 \%$ of the questions asked by teachers are actually responded to by learners. The inevitable question that is raised here and to which this study can provide no definite answer is whether in tertiary settings, or more precisely in lectures, successful education depends on question-answer interaction. Interestingly, Smit (2010: 241) showed that the international students in her hotel-management classrooms prefer some sessions to be teacher-fronted or lecture-based rather than interactive, as this grants them the opportunity to "gather a great deal of new information" without having the need to be 
exposed to interactional practices. Whether this option is preferred by the students in our data or not would need to be tested in prospective stages of research.

\section{CONCLUDING REMARKS AND PEDAGOGICAL IMPLICATIONS}

This paper focused on the use of questions by three university teachers in three different Spanish universities and across three different disciplines. Specifically, the study reported that questions are indeed used in English medium instruction lectures and that the most recurrently used by all three teachers and disciplines are, in identical order, confirmation checks, followed by self-answered questions and display questions. This overall finding seems to suggest that, at least as far as our data suggest, there are far more similarities than differences between the disciplines under scrutiny with regard to the use of questions in academic lectures. This finding matches other studies dealing with lecturing performance across disciplinary subjects (Chang 2012) and even languages (see Dafouz Milne and Núñez Perucha 2010 for a study of L1/L2 lecturing performance), thereby suggesting that maybe the generic features of lectures predominate over differences in the disciplinary culture. In other words, it could be claimed that lectures in an educational setting seem to transcend the academic disciplinary culture and exhibit certain uniformity or what we have called a common macro-structure. Admittedly, the limited size of our sample and our focus on lectures as the sole classroom speech event analysed necessitates a cautious interpretation of the findings and calls for further research.

From an EMI perspective, what remains to be answered is whether differences in teacher question types could somehow also be influenced (whether consciously or unconsciously) by considerations of language proficiency as Dalton-Puffer (2007: 125) suggested. In other words, could questions be articulated and used by teachers as a kind of scaffolding or compensatory strategy to make up for potential difficulties derived from what instructors think may be students' limited foreign language competence? Or could questions be linked to what content teachers have found to be the usual (L1) conceptual difficulties students face in university disciplines and education? In order to answer such questions, contrastive data from L1 and L2 lecturer performance might be of interest in trying to disentangle specific EMI variables from disciplinary differences 
or classroom discourse features. It might also be revealing to conduct longitudinal studies such as those by Smit (2010) and Dalton-Puffer (2007) to track possible changes in the types of teacher questions used over longer periods of time. Smit (2010), for example, found in her ethnographic study that both teachers and students varied their questioning behaviour across time and that while lecturers gradually shifted from more display questions to more referential ones, students moved from shorter, sometimes minimal one-word responses, to more extended discourse.

All in all, what is indeed a difference in this study with respect to other research conducted on teacher questions in university settings is the role of English as the medium of instruction by non-native speaker lecturers and students. In these settings, language expertise authority cannot be automatically expected from lecturers (Dafouz 2011, Hynninen 2012, Smit 2010). Consequently, an interesting shift in the traditionally hierarchical roles found in university contexts may be found, with a more "democratic stance” developing between teacher and student interaction (see Dafouz et al. 2007), as teachers often (need to) negotiate foreign language terms and expressions with students and use these as language informants. Whether this democratic, less-hierarchical atmosphere in EMI classrooms is actually deliberately enacted by teachers or the inevitable consequence of some teachers having (initially) a reduced repertoire is something to be researched ${ }^{6}$.

To conclude, with this study our intention was to raise awareness of the importance of teacher discourse, and more specifically teacher questions, in EMI settings. Our results should be interpreted with caution and may not be generalized, since the analysis has dealt with a limited-size corpus. For this reason, further research on larger sets of data needs to be undertaken so that additional conclusions may be drawn.

From a pedagogical perspective, we believe that awareness of teacher discourse is essential since the large majority of teachers working in EMI contexts (at least in Spain) are not language experts, and thus need to be trained to be attentive to their own discourse in the classroom and to realise that language can be used as a supporting strategy for student learning. Higher education teachers need to be aware of how

\footnotetext{
${ }^{6}$ Dafouz (2011: 203-204) observed, through face-to-face interviews, that teachers often expressed concern regarding their "limited" interpersonal skills when, for example, they had to solve misunderstandings, negotiate deadlines with students, or use an informal register or humorous strategies to empathise with learners.
} 
different interactional strategies (e.g. questions) can facilitate or limit the amount of content learning and language learning that students may achieve. As Stoller (2004: 45) clearly stated “(...) language [can]not be regarded as a mere vehicle for the transport of knowledge. Rather, the language itself would have to be seen as a constitutive element for the construction of knowledge". This last thought needs to be a fundamental component in the teacher education courses that different universities are devising (see Klaasen 2008) in order to provide more effective support for content teachers in this new and challenging working scenario.

\section{REFERENCES}

Bamford, J. 2005. "Interactivity in academic lectures: The role of questions and answers”. In Bamford, J. and M. Bondi (Eds.) Dialogue within Discourse Communities: Metadiscursive Perspectives on Academic Genres. Tubingen, Germany: Max Niemeyer, 123-145.

Barnes, D. 1969. “Language in the secondary classroom”. In Barnes, D., J. Britton and M. Torbe (Eds.) Language, the Learner and the School. Harmondsworth, UK: Penguin, 9-87.

Biber, D. 1993. "Representativeness in corpus design" Journal of Literary and Linguistic Computing 8 (4), 243-257.

Calderhead, J. 1981. "Stimulated recall: A method for research on teaching”. British Journal of Educational Psychology 5, 211-217.

Cazden, C.B. 1988. Classroom Discourse: The Language of Teaching and Learning. Portsmouth, NH: Heinemann.

Chang, Y. 2012. "The use of questions by professors in lectures given in English: Influences of disciplinary cultures”. English for Specific Purposes 31, 103-116.

Chaudron, C. 1988. “Teacher talk in second language classrooms”. In Chaudron, C. (Ed.) Second Language Classrooms. Cambridge: Cambridge University Press, 5089.

Coleman, J. 2006. "English-medium teaching in European higher education". Language Teaching 39, 1-14. 
Crawford Camiciottoli, B. 2004. "Interactive discourse structuring in L2 guest lectures: Some insights from a comparative corpus-based study”. English for Specific Purposes 3, 39-54.

Csomay, E. 2002. "Variation in academic lectures: Interactivity and level of instruction”. In Reppen, R.S., M. Fitmaurice and D. Biber (Eds.) Using Corpora to Explore Linguistic Variation. Amsterdam: John Benjamins, 205-224.

Dafouz, E. 2011. "English as the medium of instruction in Spanish contexts: A look at teacher discourses”. In Ruiz de Zarobe, Y., J.M. Sierra and F. Gallardo del Puerto (Eds.) Content and Foreign Language Integrated Learning. Contributions to Multilingualism in European Contexts. Bern: Peter Lang, 189 - 205.

Dafouz, E., Núñez, B., and Sancho, C. 2007. “Analysing stance in a CLIL university context: Non-native speaker use of personal pronouns and modal verbs”. International Journal of Bilingualism and Bilingual Education 10 (5), 647-662.

Dafouz, E. and Núñez, B. 2009. "CLIL in higher education: Devising a new learning landscape”. In Dafouz, E. and M.C. Guerrini (Eds.) CLIL across Educational Levels: Experiences from Primary, Secondary and Tertiary Contexts. Madrid/London: Santillana Educación / Richmond Publishing, 101-112.

Dafouz Milne, E. and Núñez Perucha, B. 2010. “Metadiscursive devices in university Lectures: A contrastive analysis of L1 and L2 teacher performance”. In DaltonPuffer, C., T. Nikula and U. Smit (Eds.) Language Use and Language Learning in CLIL Classrooms. Amsterdam: John Benjamins, 213-232.

Dafouz, E., Camacho, M., and Urquía, E. in press. “ “Surely they can’t do as well”: a comparison of business students' academic performance in English medium and Spanish-as-first-language medium programmes”. Language and Education. DOI: 10.1080/09500782.2013.808661

Dalton- Puffer, C. 2007. Discourse in Content and Language Integrated Learning (CLIL) Classrooms. Amsterdam: John Benjamins.

Dillon, J.T. 1988. “Questioning in education”. In Meyer, M. (Ed.) Questions and Questioning. Berlin: Walter de Gruyter, 98 - 117. 
Doiz, A., Lasagabaster, D. and Sierra, J.M. 2013. English-Medium Instruction at Universities. Global Challenges. Bristol: Multilingual Matters.

Duff, P. 2008. Case Study Research in Applied Linguistics. Routledge: New York/London.

Edwards, D. and Mercer, N. 1987. Common Knowledge: The Development of Understanding in the Classroom. London: Methuen.

Fortanet-Gómez, I. 2013. CLIL in Higher Education. Towards a Multilingual Language Policy. Bristol: Multilingual Matters.

Gibbons, P. 2002. Scaffolding Language, Scaffolding Learning: Teaching ESL Children in the Mainstream Classroom. Portsmouth, NH: Heinemann.

Goffman, E. 1981. “The lecture”. In Goffman, E. (Ed.) Forms of Talk. Philadelphia: University of Pennsylvania Press, 162-195.

Hynninen, N. 2012. "ICL at the micro-level: L2 speakers taking on the role of language experts”. In Smit, U. and E. Dafouz (Eds.) Integrating Content and Language in Higher Education. Gaining Insights into English-Medium Instruction at European Universities. Special Issue of AILA Review 25, 13-29.

Klaassen, R.G. 2008. "Preparing lecturers for English-medium instruction”. In Wilkinson, R. and V. Zegers (Eds.) Realizing Content and Language Integration in Higher Education. Maastricht, Netherlands: Maastricht University, 32-43.

Klaassen, R. 2008. "Preparing lecturers of English-medium instruction”. In Wilkinson, R. and V. Zegers (Eds.) Realizing Content and Language Integration in Higher

Krashen, S.D. 1985. The Input Hypothesis: Issues and Implications. London: Longman.

Long, M. 1981. “Input, interaction and second language acquisition”. In Winitz, H. (Ed.) Native Language and Foreign Language Acquisition. Annals of the New York Academy of Science, 379, 259-278.

Long, M. 1983. "Native speaker/Non-native speaker conversation and the negotiation of comprehensible input”. Applied Linguistics 4, 126-141. 
Long, M. and Sato, C.J. 1983. "Classroom foreign talk discourse: Forms and functions of teachers' questions”. In Seliger, H.W. and M.H. Long (Eds.) Classroom Oriented Research in Second Language Acquisition. Rowley, MA: Newbury House, 146-165.

Lyster, R. 2007. Learning and Teaching Languages through Content: A Counterbalanced Approach. Amsterdam/Philadelphia: John Benjamins.

Mehan, H. 1979. Learning lessons: Social Organization in the Classroom. Cambridge: Harvard University Press.

Mercer, N. 2000. Words and Minds. How We Use Language to Think Together. London: Routledge.

Morell, T. 2004. “Interactive lecture discourse for university EFL students”. English for Specific Purposes 23 (3), 325-338.

Morell, T. 2007. "What enhances EFL students' participation in lecture discourse? Student, lecturer, and discourse perspectives”. Journal of English for Academic Purposes 6 (3), 222-237.

Musumeci, D. 1996. "Teacher-learner negotiation in content-based instruction: Communication at cross purposes”. Applied Linguistics 17, 3, 286-325.

Neumann, R. 2001. “Disciplinary Differences and University Teaching”. Studies in Higher Education 2, 135-146.

Sánchez García, D. 2010. Classroom Interaction in University Settings: The Case of Questions in Three Disciplines. M.A. Thesis, Universidad Complutense de Madrid. < http://eprints.ucm.es/12793/1/Davinia_Sanchez.pdf>

Smit, U. 2010. English as a Lingua Franca in Higher Education. A Longitudinal Study of Classroom Discourse. Berlin: De Gruyter Mouton.

Smit, U. and Dafouz, E. 2012. "Integrating content and language in higher education. An introduction to English-medium policies, conceptual issues and research practices across Europe”. In Smit, U. and E. Dafouz (Eds.) Integrating Content and Language in Higher Education. Gaining Insights into English-Medium Instruction at European Universities. Special Issue of AILA Review 25, 1-12. 
Stoller, F. 2004. “Content-based instruction: Perspectives on curriculum planning”. Annual Review of Applied Linguistics 24, 261-283.

Swain, M. 1985. "Communicative competence: Some roles of comprehensible input and comprehensible output in its development”. In Gass, S. and C. Madden (Eds.) Input in Second Language Acquisition. Rowley, MA: Newbury House, 235-253.

Swain, M. 1995. “Three functions of output in second language learning”. In Cook, G. and B. Seidlhofer (Eds.) Principle and Practice in Applied Linguistics: Studies in Honour of H. G. Widdowson. Oxford: Oxford University Press, 125-144.

Tharp, R.G. and Gallimore, R.G. 1988. Rousing Minds to Life: Teaching, Learning and Schooling in Social Context. Cambridge: Cambridge University Press.

Thøgersen, J. and Airey, J. 2011. "Lecturing undergraduate science in Danish and in English: A comparison of speaking rate and rhetorical style”. English for Specific Purposes 30, $209-221$.

Thompson, S. 1998. "Why ask questions in monologue? Language choices at work in scientific and linguistic talk”. In Hunston, S. (Ed.) Language at Work. Clevedon: BAAL/Multilingual Matters, 137-150.

Van Lier, L. 1996. Interaction in the Language Curriculum: Awareness, Autonomy and Authenticity. Harlow: Longman

Vygotsky, L. 1978. Mind in Society: The Development of Higher Psychological Processes. Cambridge: Harvard University Press.

Vygotsky, L. 1989. Thought and Language. Cambridge, MA: MIT Press.

Wu, Y. and Chang, Y. 2007. “Questioning in elementary English classes co-taught by a native and a non-native English-speaking teachers". Paper presented in The second Hsinchu City's elementary school English collaborative teaching conference. Hsunchu, Taiwan: English Education Council, Hsinchu City Government.

Young, L. 1994. "University lectures - Macro-structures and micro-features”. In Flowerdew, J. (Ed.) Academic Listening. Research Perspectives. Cambridge: Cambridge University Press, 159-176. 
Received: 3 May 2013

Accepted: 24 August 2013

Cite this article as:

Dafouz Milne, E. \& Sánchez García, D. 2013. “'Does everybody understand?’ Teacher questions across disciplines in English-mediated university lectures: An exploratory study". Language Value 5 (1), 129-151. Jaume I University ePress: Castelló, Spain. http://www.erevistes.uji.es/languagevalue. DOI: http://dx.doi.org/10.6035/LanguageV.2012.5.7

ISSN 1989-7103

Articles are copyrighted by their respective authors 